\title{
Cost-effectiveness of zofenopril in patients with left ventricular systolic dysfunction after acute myocardial infarction: a post hoc analysis of SMILE-4
}

\author{
This article was published in the following Dove Press journal: \\ ClinicoEconomics and Outcomes Research \\ 5 July 2013 \\ Number of times this article has been viewed
}

\section{Claudio Borghi' \\ Ettore Ambrosioni' \\ Stefano Omboni ${ }^{2}$ \\ Arrigo FG Cicero' \\ Stefano Bacchelli \\ Daniela Degli Esposti' \\ Salvatore Novo ${ }^{3}$ \\ Dragos Vinereanu ${ }^{4}$ \\ Giuseppe Ambrosio 5 \\ Giorgio Reggiardo 6 \\ Dario Zava ${ }^{7}$ \\ 'Unit of Internal Medicine, Policlinico S Orsola, University of Bologna, Bologna, Italy; ' ${ }^{2}$ talian Institute of Telemedicine, Varese, Italy; ${ }^{3}$ Division of Cardiology, University of Palermo, Palermo, Italy; ${ }^{4}$ University and Emergency Hospital, Bucharest, Romania; ${ }^{5}$ Division of Cardiology, University of Perugia, Perugia, Italy; ${ }^{6}$ Mediservice, Milano, Italy; ${ }^{7}$ stituto Lusofarmaco d'Italia SpA, Peschiera Borromeo, Italy}

Correspondence: Claudio Borghi

Divisione di Medicina Interna,

Policlinico S Orsola, Via Massarenti 9,

Bologna 40 I 38, Italy

Tel +3905I 6363243

Fax +39051391320

Email claudio.borghi@unibo.it
Background: In SMILE-4 (the Survival of Myocardial Infarction Long-term Evaluation 4 study), zofenopril + acetylsalicylic acid (ASA) was superior to ramipril + ASA in reducing the occurrence of major cardiovascular events in patients with left ventricular dysfunction following acute myocardial infarction. The present post hoc analysis was performed to compare the cost-effectiveness of zofenopril and ramipril.

Methods: In total, 771 patients with left ventricular dysfunction and acute myocardial infarction were randomized in a double-blind manner to receive zofenopril $60 \mathrm{mg} /$ day $(\mathrm{n}=389)$ or ramipril $10 \mathrm{mg} /$ day $(\mathrm{n}=382)+$ ASA $100 \mathrm{mg}$ /day and were followed up for one year. The primary study endpoint was the one-year combined occurrence of death or hospitalization for cardiovascular causes. The economic analysis was based on evaluation of cost of medications and hospitalizations and was applied to the intention-to-treat population $(\mathrm{n}=716)$. Cost data were drawn from the National Health Service databases of the European countries participating in the study. The incremental cost-effectiveness ratio was used to quantify the cost per event prevented with zofenopril versus ramipril.

Results: Zofenopril significantly $(P=0.028)$ reduced the risk of the primary study endpoint by $30 \%$ as compared with ramipril (95\% confidence interval, $4 \%-49 \%)$. The number needed to treat to prevent a major cardiovascular event with zofenopril was 13 less than with ramipril. The cost of drug therapies was higher with zofenopril (328.78 Euros per patient per year, $n=365$ ) than with ramipril (165.12 Euros per patient per year, $\mathrm{n}=351$ ). The cost related to the occurrence of major cardiovascular events requiring hospitalization averaged 4983.64 Euros for zofenopril and 4850.01 Euros for ramipril. The incremental cost-effectiveness ratio for zofenopril versus ramipril was 2125.45 Euros per event prevented (worst and best case scenario in the sensitivity analysis was 3590.09 and 3243.96 Euros, respectively).

Conclusion: Zofenopril is a viable and cost-effective treatment for managing patients with left ventricular dysfunction after acute myocardial infarction.

Keywords: acute myocardial infarction, left ventricular dysfunction, angiotensin-converting enzyme inhibitors, zofenopril, ramipril, acetylsalicylic acid, cost-effectiveness

\section{Introduction}

The results of major clinical trials clearly demonstrate that angiotensin-converting enzyme (ACE) inhibitors effectively prevent morbidity and mortality of patients after acute myocardial infarction (AMI), particularly if associated with left ventricular dysfunction (LVD). ${ }^{1-5}$ Thus, practice guidelines now recommend that all AMI patients receive treatment with an ACE inhibitor in combination with a beta-blocker, 
a lipid-lowering agent, and acetylsalicylic acid (ASA), unless a contraindication exists. ${ }^{6-9}$

In addition, several large-scale, randomized, prospective studies have evaluated the cost-effectiveness of ACE inhibitors in the treatment of AMI and heart failure. The results of such economic analyses unanimously indicate that ACE inhibitors are cost-effective when used to treat patients after AMI, ${ }^{10-13}$ and argue for the widest possible use of ACE inhibitors in this setting. ${ }^{14-17}$

Zofenopril is a sulfhydryl-containing lipophilic ACE inhibitor with ancillary and cardioprotective properties. ${ }^{18-21}$ Following extensive evidence of its efficacy and safety derived from the randomized controlled studies of the SMILE (Survival of Myocardial Infarction Long-term Evaluation) program, zofenopril is currently indicated for treatment initiated within the first 24 hours in patients with AMI with or without signs and symptoms of heart failure, who are hemodynamically stable and have not received thrombolytic therapy. ${ }^{22,23}$ Recently, the SMILE-4 study demonstrated that the efficacy of zofenopril associated with ASA is superior to that of ramipril + ASA in patients with LVD following AMI, in terms of prevention of major cardiovascular outcomes. ${ }^{24}$

Although the clinical efficacy of zofenopril is clear from the SMILE studies, the question remains as to whether the added benefit of zofenopril is worth the added cost. For this reason, we undertook a post hoc cost-effectiveness analysis to compare the cost-effectiveness of zofenopril and ramipril in patients with LVD after an AMI.

\section{Materials and methods}

\section{Clinical trial}

The SMILE-4 trial was a large multicenter, randomized, prospective study, the methodology and results of which are reported in detail elsewhere. ${ }^{24}$ Briefly, male and nonpregnant female patients aged $18-85$ years with a confirmed diagnosis of ST or non-ST segment elevation myocardial infarction in the 24 hours preceding enrollment (not treated with primary percutaneous transluminal coronary angioplasty, treated or not with thrombolysis and recommended pharmacologic treatment) and with clinical and/or echocardiographic evidence of LVD (Killip class $>1$, plus a third heart sound, pulmonary congestion on chest $x$-ray, and/or a left ventricular ejection fraction $<45 \%$ ) were enrolled in 79 hospitals in eight European countries.

Eligible patients entered a four-day, open-label phase during which zofenopril was administered to all patients according to an uptitration scheme. On days 1 and 2, patients received zofenopril $7.5 \mathrm{mg}$ twice daily + an evening dose of ASA $100 \mathrm{mg}$. On days 3 and 4, the zofenopril dose was doubled (to $15 \mathrm{mg}$ twice daily) while the dose of ASA remained unchanged. On day 5, patients were randomized $1: 1$ in a double-blind manner to receive zofenopril $30 \mathrm{mg}$ twice daily + ASA $100 \mathrm{mg}$ once daily or ramipril $5 \mathrm{mg}$ twice daily + ASA $100 \mathrm{mg}$ once daily for 12 months. The study medications were administered in combination with standard recommended treatments for AMI, excluding ACE inhibitors, angiotensin receptor blockers, and antiplatelet drugs other than ASA, clopidogrel, or ticlopidine. Concomitant chronic anticoagulant treatment was allowed in the acute phase of myocardial infarction and in case of a specific indication, or in patients who reached a study endpoint. Patients were seen at enrollment, at randomization ( 5 days after enrollment) and after months 1, 6, and 12. Blood pressure and heart rate were measured, an echocardiogram was performed, blood samples were drawn (centralized estimation of N-terminal pro-brain natriuretic peptide), and occurrence of concomitant diseases, adverse events, use of concomitant medications, and compliance with the study drugs were checked at each study visit. A physical examination, a 12-lead electrocardiogram, and laboratory tests (hematology, clinical chemistry, and urinalysis) were performed at entry, at randomization, and at study end.

\section{Cost analysis}

The initial aim of the cost analysis was to investigate whether use of zofenopril might be cost-neutral or cost-saving. Only drug and hospitalization or event costs were included in this analysis. The perspective adopted for the study was that of a third-party payer, ie, the individual national health services of the countries participating in the study. A reference cost was obtained by averaging costs for each country and presenting them in 2012 Euros.

\section{Medications}

The unit costs of the study drugs (zofenopril, ramipril, and ASA) were derived from the national pharmaceutical formulary for each country, using the reimbursement price for the generic drug as reference. The cost of zofenopril was estimated at 0.80 Euros per day using the 28-tablet pack, that of ramipril 0.34 Euros per day using the 14-tablet pack, and that of ASA 0.10 Euro per day using the 30-tablet pack.

\section{Events}

The unit costs for post-AMI events were calculated considering a Diagnosis-Related Group code. Information on costs for each type of event and for each individual 
country was collected and averaged to obtain a reference cost. ${ }^{25}$ Because the reference payment list did not refer to a decline in left ventricular ejection fraction $>15 \%$, this cost was conservatively estimated as one-third of the cost of a hospitalization for symptomatic heart failure. The assumption underlying this choice was that a patient with such clinical worsening will experience at least one admission for symptomatic heart failure in the next three years, with no other major cardiovascular events.

\section{Statistical analysis}

The economic evaluation of SMILE-4 was based on estimation of the costs of drugs and events, and on costeffectiveness analysis. The clinical benefits were also calculated from endpoints used in the trial, and converted to the "number needed to treat", an expression of the number of patients who must be treated with one drug to prevent one adverse event. The calculation was done as follows:

1/(Relative frequency of major cardiovascular events with zofenopril - Relative frequency of major cardiovascular events with ramipril). ${ }^{26}$

The analysis was carried out in the intention-to-treat population, as for the clinical outcomes in the original study, ${ }^{24} \mathrm{ie}$, in patients treated with at least one dose of study medication and documenting at least once, the measure of the primary efficacy assessment, even in the event of protocol violation or premature withdrawal from the study.

The economic effects were established by undertaking an incremental cost-effectiveness analysis. The results of the analysis were expressed by means of an incremental costeffectiveness ratio (ICER), and calculated as incremental drug costs divided by incremental effects. The difference in the rate of occurrence of major cardiovascular events between the two study groups (first occurrence of cardiovascular death or hospitalization for cardiovascular causes, including congestive heart failure, acute myocardial infarction, angina, revascularization, or a decline in left ventricular ejection fraction $>15 \%$ ) was used as the incremental effect. This was the original primary study endpoint for the main study. ${ }^{24}$

The ICER was calculated by the following equation:

Incremental cost-effectiveness ratio

$=($ Cost of zofenopril treatment for 1 year - Cost of ramipril treatment for 1 year)/(Relative frequency of major cardiovascular events with zofenopril over one year - Relative frequency of major cardiovascular events with ramipril over one year). ${ }^{27-29}$
The cost-effectiveness study was done according to a base-case analysis supplemented with a sensitivity analysis. ${ }^{27,30}$ In the base-case analysis, exclusively average values of the model input parameters were used. In the sensitivity analysis, we assessed the impact of increasing the price of zofenopril by $20 \%$ and decreasing the price of ramipril by $20 \%$ on the cost-effectiveness of the intervention according to a deterministic one-way analytical approach. Uncertainty in the point estimate of the ICER was also investigated by varying the event size while costs remained the same or by combining changes in unit costs and event size, in order to obtain a worst/best case scenario analysis.

\section{Results \\ Clinical efficacy}

The present study analyzed the 716 patients included in the intention-to-treat analysis of the main SMILE-4 study (365 treated with zofenopril $60 \mathrm{mg}$ and 351 with ramipril $10 \mathrm{mg}$ ). No significant differences in baseline patient demographic and clinical characteristics were observed between the treatment groups (Table 1), with the only exception being the proportion of patients with arterial hypertension $(P=0.033)$, previous percutaneous transluminal coronary angioplasty $(P=0.044)$, and impaired left ventricular ejection fraction $(P=0.009)$. Further details are reported in the main study publication. ${ }^{24}$

During the 12 months of double-blind, randomized treatment, major cardiovascular events occurred in 105 of the 365 patients treated with zofenopril (29\%) and in 128 of the 351 patients treated with ramipril $(37 \%)$, with a $30 \%$ significantly $(P=0.028)$ lower risk of achieving the combined endpoint (95\% confidence interval, 4\%-49\%) in zofenopriltreated patients ${ }^{24}$ (Table 2). This figure resulted in a number needed to treat of 13 , indicating that one major cardiovascular event could be prevented with zofenopril by treating 13 fewer patients than with ramipril.

\section{Cost effectiveness}

The average cost of drug treatment per patient per year was 328.78 Euros for zofenopril + ASA and 165.12 Euros for ramipril + ASA. The cost related to occurrence of major cardiovascular events averaged 4983.64 Euros for zofenopril and 4850.01 Euros for ramipril (Table 3). When the two study groups were pooled together, the average estimated cost per event was 4910.23 Euros. Treatment with zofenopril yielded an ICER of 2125.45 Euros for any additional event prevented compared with ramipril. 
Table I Baseline demographic and clinical characteristics of the intention-to-treat population in SMILE-424 $(n=716)$

\begin{tabular}{|c|c|c|}
\hline Characteristics & $\begin{array}{l}\text { Zofenopril } \\
(\mathrm{n}=365)\end{array}$ & $\begin{array}{l}\text { Ramipril } \\
(\mathrm{n}=35 \mathrm{I})\end{array}$ \\
\hline Age (years, mean $\pm S D$ ) & $61 \pm 11$ & $61 \pm 11$ \\
\hline Males (n, \%) & $268(73)$ & $276(79)$ \\
\hline BMI $\left(\mathrm{kg} / \mathrm{m}^{2}\right.$, mean $\left.\pm \mathrm{SD}\right)$ & $28 \pm 4$ & $28 \pm 4$ \\
\hline Diabetes mellitus (n, \%) & $68(19)$ & $63(19)$ \\
\hline Treated hypercholesterolemia $(\mathrm{n}, \%)$ & $68(19)$ & $72(21)$ \\
\hline Treated arterial hypertension (n, \%) & $237(65)$ & $200(57)$ \\
\hline \multicolumn{3}{|l|}{ Relevant concomitant treatments ( $\mathrm{n}, \%)$} \\
\hline ACE inhibitors & $13(4)$ & $3(1)$ \\
\hline Angiotensin II antagonists & $4(1)$ & $I(I)$ \\
\hline Beta-blockers & $199(55)$ & $177(50)$ \\
\hline Alpha-blockers & $24(7)$ & $28(8)$ \\
\hline Calcium antagonists & $8(2)$ & $13(4)$ \\
\hline Diuretics & $73(20)$ & $74(21)$ \\
\hline Digoxin & - & $3(1)$ \\
\hline Nitrates & $128(35)$ & $117(33)$ \\
\hline Antiarrhythmic drugs & $14(4)$ & $9(3)$ \\
\hline Statins & $217(59)$ & $200(57)$ \\
\hline Other lipid-lowering drugs & $15(4)$ & $17(5)$ \\
\hline Other cardiovascular drugs & $47(13)$ & $32(9)$ \\
\hline Atrial fibrillation (n, \%) & $7(2)$ & $2(1)$ \\
\hline Peripheral arterial occlusive disease $(\mathrm{n}, \%)$ & $17(5)$ & $18(5)$ \\
\hline Previous myocardial infarction (n, \%) & $72(20)$ & $61(18)$ \\
\hline Angina pectoris (n, \%) & 140 (39) & $123(35)$ \\
\hline Prior PTCA (n, \%) & $26(7)$ & $13(4)$ \\
\hline Prior CABG (n, \%) & $6(2)$ & $6(2)$ \\
\hline Congestive heart failure (n, \%) & $24(7)$ & $25(7)$ \\
\hline PTCA performed at entry $(n, \%)$ & $115(31)$ & $109(31)$ \\
\hline $\begin{array}{l}\text { Thrombolytic therapy performed } \\
\text { at entry }(\mathrm{n}, \%)\end{array}$ & $|4|(39)$ & $134(38)$ \\
\hline $\mathrm{LVEF} \leq 40 \%(\mathrm{n}, \%)$ & $|5|(4 \mid)$ & III (32) \\
\hline $\mathrm{SBP}(\mathrm{mmHg}$, mean $\pm \mathrm{SD})$ & $139 \pm 24$ & $140 \pm 24$ \\
\hline $\mathrm{DBP}(\mathrm{mmHg}$, mean $\pm \mathrm{SD})$ & $83 \pm 14$ & $83 \pm 13$ \\
\hline HR (beats per minute, mean $\pm S D$ ) & $81 \pm 17$ & $79 \pm 16$ \\
\hline
\end{tabular}

Abbreviations: ACE, angiotensin-converting enzyme; SD, standard deviation; BMI, body mass index; PTCA, percutaneous transluminal coronary angioplasty; CABG, coronary artery bypass graft; LVEF, left ventricular ejection fraction; $\mathrm{SBP}$, systolic blood pressure; DBP, diastolic blood pressure; HR, heart rate.

\section{Sensitivity analysis}

The overall result was not modified by applying sensitivity analysis. A first analysis varying the price of zofenopril and ramipril returned an ICER of 3408.26 Euros. When the lower limit of the $95 \%$ confidence interval for the event rate was used, the ICER was 2238.82 Euros, whereas the corresponding figure was 2022.96 Euros when the upper limit was selected. The worst case scenario, determined by combination of the modified drug costs and the lower limit for event rate, gave an ICER of 3590.09 Euros, while the best case scenario returned an ICER of 3243.96 Euros.

\section{Discussion}

Economic analysis of drug treatment is increasingly incorporated routinely into many clinical trials, because
Table 2 Absolute and relative frequency (\%) for the various components of the SMILE-4 primary study endpoint (hospitalization for cardiovascular causes or cardiovascular mortality) in the intention-to-treat population of SMILE-424 $(n=716)$

\begin{tabular}{|c|c|c|}
\hline & $\begin{array}{l}\text { Zofenopril } \\
(n=365)\end{array}$ & $\begin{array}{l}\text { Ramipril } \\
(\mathrm{n}=351)\end{array}$ \\
\hline \multicolumn{3}{|c|}{ Hospitalization for cardiovascular causes (n, \%) } \\
\hline Congestive heart failure & $4(1.1)$ & $7(2.0)$ \\
\hline Acute myocardial infarction & $13(3.6)$ & $16(4.6)$ \\
\hline Angina pectoris & $20(5.5)$ & $22(6.3)$ \\
\hline $\begin{array}{l}\text { Decline in left ventricular ejection } \\
\text { fraction }>15 \%\end{array}$ & $15(4.1)$ & $28(8.0)$ \\
\hline Revascularization & $25(6.8)$ & $32(9.1)$ \\
\hline Other causes & II (3.0) & $12(3.4)$ \\
\hline Total & $88(24.1)$ & $117(33.3)$ \\
\hline Unadjusted OR (95\% Cl) & $0.64(0.46-0.88)$ & \\
\hline$P$ value & 0.006 & \\
\hline Adjusted OR $(95 \% \mathrm{Cl})$ & $0.65(0.46-0.91)$ & \\
\hline$P$ value & 0.012 & \\
\hline \multicolumn{3}{|l|}{ Cardiovascular death (n, \%) } \\
\hline Congestive heart failure & $4(I .1)$ & $2(0.6)$ \\
\hline Acute myocardial infarction & $6(1.6)$ & $\mathrm{I}(0.3)$ \\
\hline Sudden death & $6(1.6)$ & $6(1.7)$ \\
\hline Cardiac rupture & $\mathrm{I}(0.3)$ & I $(0.3)$ \\
\hline Stroke & $0(0.0)$ & $\mathrm{I}(0.3)$ \\
\hline Total & $17(4.7)$ & $11(3.1)$ \\
\hline Unadjusted OR $(95 \% \mathrm{Cl})$ & I.5। (0.70-3.27) & \\
\hline$P$ value & 0.293 & \\
\hline Adjusted OR $(95 \% \mathrm{Cl})$ & I. $18(0.5 \mathrm{I}-2.70)$ & \\
\hline$P$ value & 0.704 & \\
\hline $\begin{array}{l}\text { Overall major cardiovascular } \\
\text { events }(n, \%)\end{array}$ & $105(28.8)$ & $128(36.5)$ \\
\hline Unadjusted OR (95\% Cl) & $0.70(0.5 \mathrm{I}-0.96)$ & \\
\hline$P$ value & 0.028 & \\
\hline Adjusted OR $(95 \% \mathrm{Cl})$ & $0.68(0.49-0.95)$ & \\
\hline$P$ value & 0.024 & \\
\hline
\end{tabular}

Notes: Unadjusted and adjusted odds ratio and corresponding confidence intervals with $P$ values are also reported. OR adjustment by age, gender, glomerular filtration rate, left ventricular ejection fraction, Killip class, revascularization, diabetes, metabolic syndrome, hypercholesterolemia, low high-density lipoprotein, ST versus non-ST elevation myocardial infarction, $\mathrm{N}$-terminal pro-brain natriuretic peptide, and heart rate.

Abbreviations: $\mathrm{Cl}$, confidence interval; OR, odds ratio.

this type of information, in conjunction with the usual safety and efficacy data, is becoming more important to pharmaceutical companies, regulatory authorities, thirdparty payers, and end-users. The present study examined vis-à-vis the cost-effectiveness of two ACE inhibitors used widely in post-AMI patients with LVD, ie, zofenopril and ramipril. According to our findings, treatment with zofenopril costs between 2023 Euros (best case sensitivity analysis) and 3590 Euros (worst case analysis) to generate any additional event prevented compared with ramipril. This cost-effectiveness threshold is within the range of health care programs currently funded in developed countries which usually consider a threshold $<20,000-40,000$ USD (about 15,000-30,000 Euros) as being compatible with a 
Table 3 Unit and overall costs for treating each single event in SMILE-4

\begin{tabular}{|c|c|c|c|c|c|}
\hline \multirow[t]{2}{*}{ Outcome } & \multirow{2}{*}{$\begin{array}{l}\text { Cost per event per } \\
\text { patient (Euros) }\end{array}$} & \multicolumn{2}{|c|}{ Zofenopril $(n=365)$} & \multicolumn{2}{|c|}{ Ramipril (n = $35 \mathrm{I})$} \\
\hline & & Events (n) & Total cost (Euros) & Events (n) & Total cost (Euros) \\
\hline Congestive heart failure & 3425.51 & 4 & $13,702.04$ & 7 & $23,978.57$ \\
\hline Acute myocardial infarction & 4019.04 & 13 & $52,247.52$ & 16 & $64,304.64$ \\
\hline Angina pectoris & 2642.24 & 20 & $52,844.80$ & 22 & $58,129.28$ \\
\hline Decline in LVEF > $>15 \%$ & 1141.84 & 15 & $17,127.55$ & 28 & $31,971.43$ \\
\hline Revascularization & $10,993.14$ & 25 & $274,828.38$ & 32 & $351,780.32$ \\
\hline Other causes & 3650.20 & II & $40,152.20$ & 12 & $43,802.40$ \\
\hline Death & 4257.64 & 17 & $72,379.88$ & 11 & $46,834.04$ \\
\hline Overall cost & & & $523,282.37$ & & $620,800.68$ \\
\hline Average cost per patient & & & 4983.64 & & 4850.01 \\
\hline
\end{tabular}

Note: Number of occurrences for each outcome is also indicated.

Abbreviation: LVEF, left ventricular ejection fraction.

highly cost-effective treatment in the management of heart disease. 10,31,32 $^{2}$

As summarized in Table 4, the cost-effectiveness ratio calculated for zofenopril also appears favorable compared with many other strategies for the management of AMI or stable angina, including drug treatment, thrombolysis, percutaneous coronary intervention, or coronary artery

Table 4 Cost-effectiveness of various interventions versus standard care in the management of acute myocardial infarction

\begin{tabular}{|c|c|}
\hline Strategy & $\begin{array}{l}\text { Cost effectiveness } \\
\text { (Euros/YLS or } \\
\text { QALYS) }\end{array}$ \\
\hline \multicolumn{2}{|l|}{ Drugs } \\
\hline $\begin{array}{l}\text { Medical treatment alone in patients } \\
\text { with multivessel } C A D \text { and normal } \mathrm{EF}^{33}\end{array}$ & 7000 \\
\hline$\beta$-blocker in high risk post-AMI patients ${ }^{10}$ & 2800 \\
\hline$\beta$-blocker in low risk post-AMI patients ${ }^{10}$ & 15,600 \\
\hline $\begin{array}{l}\text { Captopril in post-AMI patients with } \\
\mathrm{EF} \leq 40 \%{ }^{10}\end{array}$ & 21,900 \\
\hline \multicolumn{2}{|l|}{ Reperfusion therapy } \\
\hline Thrombolysis $^{13}$ & 1750 \\
\hline Streptokinase in elderly ( $\geq 75$ years) & 21,400 \\
\hline \multicolumn{2}{|l|}{ AMI patients ${ }^{10}$} \\
\hline Primary PTCA ${ }^{13,33}$ & $8800-15,400$ \\
\hline $\begin{array}{l}\text { Primary PTCA in patients with large } \\
\text { infarct size }\end{array}$ & 34,500 \\
\hline $\begin{array}{l}\text { PTCA in patients with multivessel CAD } \\
\text { and normal } \mathrm{EF}^{33}\end{array}$ & 15,400 \\
\hline Non-elective PTCA with stenting ${ }^{36}$ & $14,500-33,900$ \\
\hline $\begin{array}{l}\text { PTCA in addition to optimal medical } \\
\text { therapy in presence of stable angina }{ }^{35}\end{array}$ & 24,805 \\
\hline $\begin{array}{l}C A B G \text { in patients with multivessel CAD } \\
\text { and normal } E F(C A B G)^{33}\end{array}$ & 14,100 \\
\hline $\begin{array}{l}\mathrm{CCU} \text { in patients with highly probable } \\
(\geq 50 \%) \mathrm{MI}^{10}\end{array}$ & 27,000 \\
\hline \multicolumn{2}{|c|}{$\begin{array}{l}\text { Note: The strategy, along with its cost-effectiveness, expressed in } 2012 \text { Euros } \\
\text { per year life saved or quality-adjusted life-year is reported. }\end{array}$} \\
\hline \multicolumn{2}{|c|}{$\begin{array}{l}\text { Abbreviations: AMI, acute myocardial infarction; CABG, coronary artery bypass } \\
\text { graft; CCU, coronary care unit; CAD, coronary artery disease; EF, ejection fraction; } \\
\text { PTCA, percutaneous transluminal coronary angioplasty; YLS, year life saved; } \\
\text { MI, myocardial infarction; QALYs, quality-adjusted life-years. }\end{array}$} \\
\hline
\end{tabular}

bypass grafting. ${ }^{10,13,31-36}$ In addition, the estimated costeffectiveness of zofenopril compares well with that of other ACE inhibitors, although such a comparison, discussed in the next paragraphs, has limitations because the model used varies between studies. A recently published economic analysis of diverse cardiologic interventions from 2000 to 2010 in England and Wales showed reasonable cost-effectiveness for ACE inhibitors, ranging from approximately 2500 Euros up to 4400 Euros for secondary prevention in heart failure patients. ${ }^{13}$ Concerning a comparison with specific ACE inhibitors, the incremental cost per life-year gained using prophylactic captopril in survivors of AMI with a reduced left ventricular ejection fraction in the SAVE study ranged between 800 and 8000 Euros, depending on age, country, and time period considered. ${ }^{37-40}$ In the GISSI-3 trial, which assessed the efficacy of early (within 24 hours) treatment with lisinopril in unselected patients with AMI, the comparative cost-effectiveness ratio for use of lisinopril, expressed as cost per additional survivors among patients randomized to receive lisinopril, was approximately 1600 Euros per life saved. ${ }^{41}$ In the TRACE study, the ICER of treating post-AMI patients with LVD with trandolapril rather than with placebo was estimated at approximately 900 Euros. ${ }^{15}$ In the patients with stable coronary artery disease included in EUROPA, the median incremental cost of perindopril for each qualityadjusted life-year gained was estimated to be about 12,000 Euros. ${ }^{17}$

The cost-effectiveness of ramipril versus placebo has been estimated in two large, randomized, prospective studies, ie, HOPE and AIRE. In the HOPE study, which recruited patients with an increased risk of cardiovascular events, the estimated cost-effectiveness of ramipril ranged between 4000 and 14,000 Euros per life-year gained at five years, depending on the various local economic analyses, with costs consistently decreasing for lifetime treatment. ${ }^{42-48}$ In the USA and Canada, the majority of patients in the HOPE study 
fell into a cost-effectiveness situation with an ICER $<8000$ Euros per primary event saved. ${ }^{16}$ In the AIRE study, the incremental cost of ramipril per life-year gained in patients with heart failure following AMI ranged between 1300 and 3900 Euros after 3.8 years of follow-up in three European subanalyses. ${ }^{49-51}$

There are a number of limitations to our economic analysis. First, and more importantly, this cost analysis was conducted after the randomized trial had been completed. Thus, a limited amount of variables were available to enable us to measure health care utilization in detail. Although some indicators useful for a more indepth pharmacoeconomic analysis, such as quality of life or life-years gained, were not assessed, hospitalizations and related causes were recorded prospectively at the time of the original study and were classified correctly using an event-driven system, ie, Diagnosis-Related Group code.

Second, a third-party payer perspective as an integrated public health care system where all costs are recorded was chosen for the cost analysis. Although it is suggested that a societal perspective be considered, it is recognized that use of other perspectives is acceptable and might be more appropriate in some cases. ${ }^{28,29}$ Unfortunately, we were forced to consider costs from the perspective of the health care system because of the limitations of the data available to us.

Third, one cost item (decline in left ventricular ejection fraction) was missing, but the assumption made does not appear to have had a major impact on the positive cost-benefit ratio of use of zofenopril versus ramipril. In fact, the number of patients with a significant reduction in left ventricular ejection fraction was larger in the ramipril-treated group, so the cost-benefit ratio of zofenopril would have been still in favor of this drug, even if the actual number of hospital admissions per year was significantly different from the number assumed in the calculations.

Fourth, our economic analysis applies to a relatively limited time horizon (one year), and we do not know whether the cost-effectiveness ratio remains favorable even if clinical benefit is assumed to stop at the end of the clinical trial follow-up period. Whilst this lack of continuing effect is implausible, any quantification of benefit beyond this period is not possible, and we cannot address the issue of how long zofenopril should be taken.

Fifth, in common with most economic analyses of this type, cost calculations were limited to the medical costs of both treatments, and nonmedical costs, direct and indirect, such as those due to productivity losses, were not evaluated or taken into account. In addition, due to the perspective and time span of the observation, we did not assess direct costs, such as rehabilitation and long-term care.

Finally, we did not compare the cost-effectiveness of zofenopril versus placebo, but versus another ACE inhibitor. However, zofenopril was cost-saving compared with ramipril, a drug already proven to be cost-effective in patients at high risk of cardiovascular disease, including post-AMI patients. ${ }^{42-51}$

\section{Conclusion}

The use of zofenopril in patients with LVD following AMI is not only associated with a $30 \%$ reduction in the risk of major cardiovascular events over one year, but also appears to be a good strategy from a health economics perspective. The incremental cost of zofenopril in the SMILE-4 Study was lower than the apparent threshold used to define a cardiac treatment as highly cost-effective $(15,000-30,000$ Euros). In addition, the cost-effectiveness of zofenopril in our study (just over 2000 Euros) compares favorably with that observed for ramipril in high cardiovascular risk and post-AMI patients (1300-14,000 Euros) and for other ACE inhibitors, such as captopril (800-8000 Euros), lisinopril (1600 Euros), trandolapril (900 Euros), and perindopril (12,000 Euros). Therefore, our results place zofenopril among the viable and cost-effective options for treating post-AMI patients with LVD.

\section{Acknowledgment}

This paper is published on behalf of the SMILE-4 working party. The authors are grateful for the financial support of Menarini International Operations Luxembourg SA, Laboratori Guidotti SpA, and Istituto Lusofarmaco d'Italia SpA.

\section{Disclosure}

$\mathrm{CB}$ is a shareholder in Abbott and BMS, and a consultant to Boehringer Ingelheim and Menarini International Consultancy. DZ is an employee of Istituto Lusofarmaco d'Italia SpA. None of the other authors have any conflicts of interest to disclose.

\section{References}

1. [No authors listed]. Indications for ACE inhibitors in the early treatment of acute myocardial infarction: systematic overview of individual data from 100,000 patients in randomized trials. ACE Inhibitor Myocardial Infarction Collaborative Group. Circulation. 1998;97:2202-2212.

2. Baker WL, Coleman CI, Kluger J, et al. Systematic review: comparative effectiveness of angiotensin-converting enzyme inhibitors or angiotensin II-receptor blockers for ischemic heart disease. Ann Intern Med. 2009;151:861-871. 
3. Flather MD, Yusuf S, Køber L, et al. Long-term ACE-inhibitor therapy in patients with heart failure or left-ventricular dysfunction: a systematic overview of data from individual patients. ACE-Inhibitor Myocardial Infarction Collaborative Group. Lancet. 2000;355:1575-1581.

4. [No authors listed]. Effects of ramipril on cardiovascular and microvascular outcomes in people with diabetes mellitus: results of the HOPE study and MICRO-HOPE substudy. Heart Outcomes Prevention Evaluation Study Investigators. Lancet. 2000;355:253-259.

5. Fox KM; EURopean trial On reduction of cardiac events with Perindopril in stable coronary Artery disease Investigators. Efficacy of perindopril in reduction of cardiovascular events among patients with stable coronary artery disease: randomised, double-blind, placebo-controlled, multicentre trial (the EUROPA study). Lancet. 2003;362:782-788.

6. Van de Werf F, Bax J, Betriu A, et al; ESC Committee for Practice Guidelines. Management of acute myocardial infarction in patients presenting with persistent ST-segment elevation: the Task Force on the Management of ST-Segment Elevation Acute Myocardial Infarction of the European Society of Cardiology. Eur Heart J. 2008;29 2909-2945.

7. Antman EM, Anbe DT, Armstrong PW, et al. ACC/AHA guidelines for the management of patients with ST-elevation myocardial infarction; a report of the American College of Cardiology/American Heart Association Task Force on Practice Guidelines (Committee to Revise the 1999 Guidelines for the Management of patients with acute myocardial infarction). J Am Coll Cardiol. 2004;44:E1-E211.

8. Fox K, Garcia MA, Ardissino D, et al; Task Force on the Management of Stable Angina Pectoris of the European Society of Cardiology; ESC Committee for Practice Guidelines (CPG). Guidelines on the management of stable angina pectoris: executive summary: The Task Force on the Management of Stable Angina Pectoris of the European Society of Cardiology. Eur Heart J. 2006;27:1341-1381.

9. López-Sendón J, Swedberg K, McMurray J, et al; Task Force on ACE-inhibitors of the European Society of Cardiology. Expert consensus document on angiotensin converting enzyme inhibitors in cardiovascular disease. The Task Force on ACE-inhibitors of the European Society of Cardiology. Eur Heart J. 2004;25:1454-1470.

10. Kupersmith J, Holmes-Rovner M, Hogan A, Rovner D, Gardiner J. Cost-effectiveness analysis in heart disease, Part III: Ischemia, congestive heart failure, and arrhythmias. Prog Cardiovasc Dis. 1995;37: 307-346.

11. Reeder CE, Gourley GA, Wurtzbacher JD, Reed P. The impact of angiotensin-converting enzyme inhibitors on managed care: economic, clinical, and humanistic outcomes. Am J Manag Care 2000;6(Suppl 3):S112-S128.

12. Davie AP. ACE inhibitors after myocardial infarction. Clinical and economic considerations. Pharmacoeconomics. 2000;17:237-243.

13. Fidan D, Unal B, Critchley J, Capewell S. Economic analysis of treatments reducing coronary heart disease mortality in England and Wales, 2000-2010. QJM. 2007;100:277-289.

14. McMurray JJ, McGuire A, Davie AP, Hughes D. Cost-effectiveness of different ACE inhibitor treatment scenarios post-myocardial infarction. Eur Heart J. 1997;18:1411-1415.

15. LePen C, Lilliu H, Keller T, Fiessinger S. The economics of TRACE. A cost-effectiveness analysis of trandolapril in postinfarction patients with left ventricular dysfunction. Pharmacoeconomics. 1998;14:49-58.

16. Lamy A, Yusuf S, Pogue J, Gafni A; Heart Outcomes Prevention Evaluation Investigators. Cost implications of the use of ramipril in high-risk patients based on the Heart Outcomes Prevention Evaluation (HOPE) study. Circulation. 2003;107:960-965.

17. Briggs A, Mihaylova B, Sculpher M, et al; EUROPA Trial Investigators. Cost effectiveness of perindopril in reducing cardiovascular events in patients with stable coronary artery disease using data from the EUROPA study. Heart. 2007;93:1081-1086.

18. Bozcali E, Dedeoglu DB, Karpuz V, Suzer O, Karpuz H. Cardioprotective effects of zofenopril, enalapril and valsartan against ischaemia/ reperfusion injury as well as doxorubicin cardiotoxicity. Acta Cardiol. 2012;67:87-96.
19. Gómez-Roso M, Montero MJ, Carrón R, Sevilla MA. Cardiovascular changes in spontaneously hypertensive rats are improved by chronic treatment with zofenopril. Br J Pharmacol. 2009;158:1911-1921.

20. Evangelista S, Manzini S. Antioxidant and cardioprotective properties of the sulphydryl angiotensin-converting enzyme inhibitor zofenopril. J Int Med Res. 2005;33:42-54.

21. Przyklenk K, Kloner RA. "Cardioprotection" by ACE-inhibitors in acute myocardial ischemia and infarction? Basic Res Cardiol. 1993;88 Suppl 1:139-154.

22. Ambrosioni E. Defining the role of zofenopril in the management of hypertension and ischemic heart disorders. Am J Cardiovasc Drugs. 2007;7:17-24

23. Borghi C, Bacchelli S, Degli Esposti D, Ambrosioni E. A review of the angiotensin-converting enzyme inhibitor, zofenopril, in the treatment of cardiovascular diseases. Expert Opin Pharmacother. 2004;5: 1965-1977.

24. Borghi C, Ambrosioni E, Novo S, Vinereanu D, Ambrosio G; SMILE-4 Working Party. Comparison between zofenopril and ramipril in combination with acetylsalicylic acid in patients with left ventricular systolic dysfunction after acute myocardial infarction: results of a randomized, double-blind, parallel-group, multicenter, European study (SMILE-4). Clin Cardiol. 2012;35:416-423.

25. Diagnosis-Related Groups in Europe: Towards Efficiency and Quality. Available from: http://www.eurodrg.eu/. Accessed April 8, 2013.

26. Cook RJ, Sackett DL. The number needed to treat: a clinically useful measure of treatment effect. BMJ. 1995;310:452-544.

27. Simoens S. Health economic assessment: a methodological primer. Int J Environ Res Public Health. 2009;6:2950-2966.

28. Gold MR, Siegel JE, Russel LB, Weinstein MC. Cost-Effectiveness in Health and Medicine. New York, NY: Oxford University Press; 1996.

29. Drummond MF, O'Brien B, Stoddart GL, Torrance GW. Methods for the Economic Evaluation of Health Care Programmes, 2nd ed. Oxford, UK: Oxford Medical Publication; 1997.

30. Grieve AP. Issues for statisticians in pharmaco-economic evaluations. Stat Med. 1998;17:1715-1723.

31. Martin S, Rice N, Smith PC. Does health care spending improve health outcomes? Evidence from English programme budgeting data. $J$ Health Econ. 2008;27:826-842.

32. Braithwaite RS, Mentor SM. Identifying favorable-value cardiovascular health services. Am J Manag Care. 2011;17:431-438.

33. Vieira RD, Hueb W, Hlatky M, et al. Cost-effectiveness analysis for surgical, angioplasty, or medical therapeutics for coronary artery disease: 5-year follow-up of Medicine, Angioplasty, or Surgery Study (MASS) II Trial. Circulation. 2012;126(11 Suppl 1): S145-S150.

34. Liu Y, Dalal K. Review of cost-effectiveness analysis of medical treatment for myocardial infarction. Int J Prev Med. 2011;2:64-72.

35. Gorenoi V, Schönermark MP, Hagen A. Percutaneous coronary intervention with optimal medical therapy versus. optimal medical therapy alone for patients with stable angina pectoris. GMS Health Technol Assess. 2011;7:Doc07.

36. Hill RA, Boland A, Dickson R, et al. Drug-eluting stents: a systematic review and economic evaluation. Health Technol Assess. 2007;11: iii, $x i-221$.

37. Mantovani LG, Belisari A, Szucs TD. Captopril in the management of patients after acute myocardial infarctions. A cost effectiveness analysis in Italy. Pharmacol Res. 1998;37:345-351.

38. Hummel S, Piercy J, Wright R, Davie A, Bagust A, McMurray J. An economic analysis of the Survival and Ventricular Enlargement (SAVE) Study. Application to the United Kingdom. Pharmacoeconomics. 1997;12(2 Pt 1):182-192.

39. Michel BC, Al MJ, Remme WJ, et al. Economic aspects of treatment with captopril for patients with asymptomatic left ventricular dysfunction in The Netherlands. Eur Heart J. 1996;17:731-740.

40. Tsevat J, Duke D, Goldman L, et al. Cost-effectiveness of captopril therapy after myocardial infarction. $J \mathrm{Am}$ Coll Cardiol. 1995;26:914-919. 
41. Franzosi MG, Maggioni AP, Santoro E, Tognoni G, Cavalieri E. Cost-effectiveness analysis of early lisinopril use in patients with acute myocardial infarction. Results from GISSI-3 trial. Pharmacoeconomics. 1998; 13:337-346.

42. Capri S, Perlini S. Cost-effectiveness in Italy of preventive treatment with ramipril in patients at high risk of cardiovascular events. Curr Med Res Opin. 2005;21:913-921.

43. Schädlich PK, Brecht JG, Rangoonwala B, Huppertz E. Cost effectiveness of ramipril in patients at high risk for cardiovascular events:economic evaluation of the HOPE (Heart Outcomes Prevention Evaluation) study for Germany from the Statutory Health Insurance perspective. Pharmacoeconomics. 2004;22:955-973.

44. Aurbach A, Russ W, Battegay E, et al. Cost-effectiveness of ramipril in patients at high risk for cardiovascular events: a Swiss perspective. Swiss Med Wkly. 2004;134:399-405.

45. Smith MG, Neville AM, Middleton JC. Clinical and economic benefits of ramipril: an Australian analysis of the HOPE study. Intern Med J. 2003;33:414-419.

46. Hart WM, Rubio-Terrés C, Margalet Fernández I, González Juanatey JR. Cost-effectiveness analysis of ramipril treatment of patients at high-risk of cardiovascular events in Spain. An Med Interna. 2002;19:515-520. Spain.
47. Björholt I, Andersson FL, Kahan T, Ostergren J. The cost-effectiveness of ramipril in the treatment of patients at high risk of cardiovascular events: a Swedish sub-study to the HOPE study. J Intern Med. 2002;251: 508-517.

48. Malik IS, Bhatia VK, Kooner JS. Cost effectiveness of ramipril treatment for cardiovascular risk reduction. Heart. 2001;85:539-543.

49. Hart WM, Rubio-Terres C, Pajuelo F, González Juanatey JR. Cost-effectiveness of the treatment of heart failure with ramipril: a Spanish analysis of the AIRE study. Eur J Heart Fail. 2002;4:553-558.

50. Schädlich PK, Huppertz E, Brecht JG. Cost-effectiveness analysis of ramipril in heart failure after myocardial infarction. Economic evaluation of the Acute Infarction Ramipril Efficacy (AIRE) study for Germany from the perspective of Statutory Health Insurance. Pharmacoeconomics. 1998;14:653-669.

51. Erhardt L, Ball S, Andersson F, Bergentoft P, Martinez C. Cost effectiveness in the treatment of heart failure with ramipril. A Swedish substudy of the AIRE study. Acute Infarction Ramipril Efficacy. Pharmacoeconomics. 1997;12(2 Pt 2):256-266. 


\section{Appendix: SMILE-4 working party Coordinators}

Ettore Ambrosioni (Bologna), Claudio Borghi (Bologna).

\section{Study centers}

Greece, Dimitrios Alexopolulus, Ioannis Nanas; Italy, Marco Agrusta, Antonio Barsotti, Serena Bergerone, Luigi Caliendo, Pio Caso, Antonio Castello, Domenico Cianflone, Tommaso Cipolla, Gaetano De Ferrari, Giuseppe De Nittis, Livio Dei Cas, Paolo Di Pasquale, Rosario Evola, Luciano Fattore, Raffaele Ferrante, Antonio Fiscella, Achille Gaspardone, Giuseppe Ielasi, Niccolò Marchionni, Giancarlo Marenzi, Filippo Marte, Federico Miccoli, Patrizia Noussan, Salvatore Novo, Mario Orlandi, Giancarlo Piovaccari, Maurizio Porcu, Patrizia Presbitero, Antonio Raviele, Emiliano Renaldini, Jorge Salerno Uriarte, Giovanni Storti, Corrado Tamburino, Pierfranco Terrosu, Roberto Testa, Rita Trinchero, Bernardino Tuccillo, Ludovico Vasquez, Giovanni Quinto Villani; Portugal, Mario Garcia Alvés, Aurora Andrade, Silva Cardoso, Josè Ilidio Moreira; Romania, Georgescu Catalina Arsenescu, Mircea Cinteza, Maria Dorobantu Dominic, Ionescu, Ioan Manitiu, Florin
Ortan, Calin Pop, Mariana Radoi, Dragos Vinereanu; Russia, Yuriy Alexandrovich Vasyuk, Victor Avenirovitch Kostenko, Yuriy Borisovich Karpov, Vira Iosifovna Tseluiko, Abram Lvovich Syrkin, Boris Mikhailovich Goloschekin, Evgeniy Mikhaylovich Nifontov, Sergey Nikolaevich Tereschenko, Natalia Nikolaevna Burova, Konstantin Nikolayevich Zrazheversusky, Grigory Pavlovich Arutuynov, Valentin Sergeevich Moiseev, Leonid Victorovich Rudenko, Alexander Yurievich Vishneversusky; Spain, Diaz De La Yera, Fernández Romero; Turkey, Cevat Kirma, Kayikcioglu Meral, Abdurrahman Oğuzhan, Dilek Ural Komsuoglu; Ukraine, Olena Ankindinovna Koval, Alexan Nikolaevich Parkhomenko, Igor Petrovich Vakalyuk, Mykola Tihonovich Vatutin, Valerii Vladimirovich Batushkin.

\section{Independent end-point and safety committee}

G Ambrosio (Perugia), A Mugelli (Firenze), F Mascagni (Firenze).

\section{Statistician}

G Boissard (Milano).
ClinicoEconomics and Outcomes Research

\section{Publish your work in this journal}

ClinicoEconomics \& Outcomes Research is an international, peerreviewed open-access journal focusing on Health Technology Assessment, Pharmacoeconomics and Outcomes Research in the areas of diagnosis, medical devices, and clinical, surgical and pharmacological intervention. The economic impact of health policy and health systems

\section{Dovepress}

organization also constitute important areas of coverage. The manuscript management system is completely online and includes a very quick and fair peer-review system, which is all easy to use. Visit http://www.dovepress.com/testimonials.php to read real quotes from published authors. 